AIC ANNALS JOURNAL CLUB

\title{
The Surprising Chronicity of Abdominal Pain in Children
}

Ann Fam Med 2013;11:iii. doi:10.1370/afm.1255.

$\mathrm{T}$ The Annals of Family Medicine encourages readers to develop a learning community of those seeking to improve health care and health through enhanced primary care. You can participate by conducting a RADICAL journal club and sharing the results of your discussions in the Annals online discussion for the featured articles. RADICAL is an acronym for Read, Ask, Discuss, Inquire, Collaborate, Act, and Learn. The word radical also indicates the need to engage diverse participants in thinking critically about important issues affecting primary care and then acting on those discussions. ${ }^{1}$

\section{HOW IT WORKS}

In each issue, the Annals selects an article or articles and provides discussion tips and questions. We encourage you to take a RADICAL approach to these materials and to post a summary of your conversation in our online discussion. (Open the article online and click on "TRACK Comments: Submit a response.") You can find

discussion questions and more information online at: http://www.AnnFamMed.org/AJC/.

\section{CURRENT SELECTION}

\section{Article for Discussion}

Lisman-van Leeuwen Y, Spee LAA, Benninga MA, Bierma-Zeinstra SMA Berger MY. Prognosis of abdominal pain in children in primary care-a prospective cohort study. Ann Fam Med. 2013;11(3):238-244.

\section{Discussion Tips}

This cohort study gives us a chance to see the big picture about abdominal pain in children that otherwise would become apparent only across a professional lifetime and then only with great attention.

\section{Discussion Questions}

- What are the study's research questions and hypotheses, and why do they matter?

- How does this study advance beyond previous research and clinical practice on this topic?

- How strong is the study design for answering the question?

- To what degree can the findings be accounted for by:

1. How patients were selected, excluded, or lost to follow-up over multiple time points?

2. How the main variables were measured?

3. Confounding (false attribution of causality because 2 variables discovered to be associated actually are associated with a 3 rd factor)?

4. Chance?

5. How the findings were interpreted?

- How were possible biases controlled for in analyses?

- How do the sensitivity analyses affect your confidence in the findings?

- What are the main study findings?

- Does it surprise you how often pain is chronic among children complaining of abdominal pain?

- How comparable is the study sample to similar patients in your practice? What is your judgment about the transportability of the findings?

- How might the findings of this study affect your diagnostic approach to children complaining of abdominal pain?

- How might the findings of this study influence how you talk with parents and children complaining of abdominal pain?

- How might this study change your practice?

- What researchable questions remain?

\section{References}

1. Stange KC, Miller WL, McLellan LA, et al. Annals Journal Club: It's time to get RADICAL. Ann Fam Med. 2006;4(3):196-197. http:// annfammed.org/cgi/content/full/4/3/196. 